\title{
Prevention of pediatric chronic kidney disease
}

\begin{abstract}
Prevention of kidney disease must begin before a woman becomes pregnant. For this prevention, it is necessary to act with doctors, health professionals, parents, schools and the community. This early prevention is important because the pathophysiology of chronic noncommunicable diseases in adults would be related to events that occur during the prenatal period and in the first year of life. In an unfavorable intrauterine environment, the embryo/ fetus undergoes adaptations resulting from epigenetics and intrinsic factors that could cause a renal maturation compromised. This is what we call fetal and perinatal programming of kidney diseases in adults. There are three types of prevention: the primary that aims to eliminate or reduce exposure to risk factors for chronic kidney disease, the secondary that eliminates or reduces exposure to risk factors and the tertiary that reduces or postpones long-term disease complications. However, the best and most effective prevention is the primary one with actions to control the future mother, the pregnant woman, the infant and older children until adolescence. The main primary prevention agents for kidney disease include the community, doctors and other health professionals, parents and caregivers, schools and day care centers. In this way, it will be possible to control the explosion of chronic kidney disease worldwide.
\end{abstract}

Keywords: chronic kidney diseases, primary prevention, fetus, embryo,infants
Volume 8 Issue 5 - 2020

\author{
Rejane de Paula Bernardes,' Nilzete Liberato \\ Bresolin, ${ }^{2}$ Maria Goretti Moreira Guimarães \\ Penido ${ }^{3}$ \\ 'Pediatric Nephrology - Clinica Nefrokids, Paraná, Brazil \\ ${ }^{2}$ Santa Catarina Federal University, Santa Catarina, Brazil \\ ${ }^{3}$ Pediatric Nephrology Unit of Nephrology Center of Santa Casa \\ de Belo Horizonte Hospital, Minas Gerais, Brazil and Pediatric \\ Nephrology Unit - Clinics Hospital - Pediatrics Department - \\ Federal University of Minas Gerais - Minas Gerais, Brazil
}

\begin{abstract}
Correspondence: Maria Goretti Moreira Guimarães Penido, Pediatric Nephrology Unit of Nephrology Center of Santa Casa de Belo Horizonte Hospital, Minas Gerais, Brazil and Pediatric Nephrology Unit - Clinics Hospital - Pediatrics Department Federal University of Minas Gerais - Minas Gerais, Brazil, Rua Piauí, 420 Santa Efigênia, Belo Horizonte, Minas Gerais, Brasil, CEP: 30I50-320,Email mariagorettipenido@yahoo.com.br
\end{abstract}

Received: September 30, 2020 | Published: October 23, 2020
Abbreviations: CKD, chronic kidney disease; RRT, renal replacement therapy; NCDA, non-communicable chronic diseases of adults; AGA, appropriate for gestational age; LGA, large for age gestational age; SGA, small for gestational age; FGR, fetal growth restriction

\section{Introduction}

Chronic kidney disease (CKD) has become a major public health problem due to the increase in its incidence and prevalence. It has high morbidity and mortality, has a long and insidious course, and is generally asymptomatic in its early stages. Patients in advanced stage of CKD have reduced life expectancy, increased risk of cardiovascular disease, significant dietary restrictions and use of a large number of medications, which considerably worsens quality of life. These patients often progress to complete loss of renal function, require renal replacement therapy (RRT) to survive, and this treatment is highly complex and expensive. Unlike adults, in which diabetes mellitus and hypertension are the main etiologies of CKD, in children, congenital causes are responsible for most of all cases. While this is the most common etiology in children in developed countries, where CKD is diagnosed at an early stage, acquired or infectious causes predominate in developing countries, where patients are referred in the late stages of CKD. ${ }^{1}$ The epidemiology of this disease in the pediatric population is not yet fully established. Unfortunately, most data are still underestimated because the registration is only performed when the individual already needs dialysis. ${ }^{2-5}$ Pediatric CKD presents peculiar characteristics and challenges that are not faced by adult patients and that make it a unique entity.

These peculiarities include growth retardation, nutritional changes and psychosocial maladjustment, which considerably impact the quality of life of these patients. ${ }^{6-8}$ Furthermore, the complications of this disease in childhood can have consequences that will influence the renal health of adults. Thus, pediatric nephrologists or nephrologists who care for adult patients, when caring for children with CKD should have a look to the future, and when caring for adults they should have a look at the past, forming a global view of their patients. Considering that CKD is a threat to public health, with increasing prevalence, high costs and poor results, broader efforts should focus on its prevention and early detection. The Centers for Disease Control and Prevention have launched public health strategies to prevent the development, progression and complications of the disease in the United States. Strategies for primary, secondary and tertiary prevention of chronic diseases have been defined, including CKD. ${ }^{9}$ The World Health Organization has been outlining strategies to reduce mortality from chronic non-communicable diseases by 2022. To achieve these objectives the cooperation between government organizations, hospitals, health professionals, patients and families and the general public will be necessary to understand the following message: " $\mathrm{CKD}$ is common, harmful and treatable". ${ }^{10}$

\section{Fetal programming and chronic adult diseases}

In Pediatrics, kidney diseases can be "silent" with nonspecific signs and symptoms that can result in harmful consequences at the renal and systemic level. It is necessary for pediatricians and family doctors to take primary preventive measures aimed at eliminating or reducing exposure to risk factors for CKD. ${ }^{11}$ Studies have demonstrated the importance of maternal influence and intrauterine life during the child's development. ${ }^{12}$ Then, a question arises: when should kidney disease prevention begin? In the childhood? During the pregnancy? In fact, prevention of kidney disease must begin before a woman becomes pregnant. For this to happen, action is needed with doctors, health professionals, parents, schools and the community. ${ }^{13}$ And why is it so important? In 1986, the epidemiologist David Barker proposed the theory of a fetal and infantile origin for adult diseases: "Adverse environments during fetal life and early childhood imply an increased risk of illness during adulthood." 14,15 It is called fetal and infant programming of non-communicable chronic diseases of adults (NCDA) and the term "programming" postulates that stimuli or insults during critical periods of development can have a lasting 
and permanent impact throughout an individual's life. Thus, NCDA have a fetal and postnatal programming. ${ }^{16}$

This process results from changes in the balance of natural environmental factors that, in the case of the developing fetus, comes from the intrauterine environment and from signals that the pregnant mother transfers to her child through the placenta (product of the diet, exposure to the environment, pollution, drugs, etc). ${ }^{17}$ The factors that induce fetal programming are varied and not yet fully understood. Permanent structural changes in organs and cells, long-term adjustments of endocrine regulators and altered gene transcription (epigenetic phenomenon) have been identified. ${ }^{18}$ Studies on fetal renal programming in humans have shown that there are critical periods of development and long-term sequelae. Researchers have been looking for interventional approaches to "reprogram" renal susceptibility in relation to various diseases. ${ }^{16-18}$ The factors associated with fetal growth can be divided into:

I. Maternal: maternal nutrition (mainly proteins and glucose); consumption of illicit drugs alcohol and tobacco; hypertension; pre-eclampsia; primiparity; maternal overweight / obesity; mother born small for gestational age or with fetal growth restriction; asthma; polycystic ovary syndrome.

II. Placental: changes in uterus - placental circulation; changes in nutrient transfer; placental infarction; abnormal development of the placenta.

\section{Fetal: chromosomal abnormalities. ${ }^{19}$}

There is evidence that at the cellular level, epigenetic mechanisms would participate in the fetal programming process. These mechanisms comprise a series of chemical changes in the DNA and proteins that interact with it, which shape and regulate the expression of genes, without changing the genetic code. ${ }^{12,20}$ During the first stages of fetal development, there is a high capacity for adaptation to the environment and this plasticity is highly sensitive to these environmental factors. As a result of this genome-environment interaction, the organism generates a repertoire of responses to "probable events" with purpose of adjusting better to this environment. For example, poor maternal nutrition during pregnancy generates signals that put the fetus on alert, suggesting the existence of an environment lacking in nutrients. The fetus responds with adaptations such as a smaller size and a more parsimonious and reduced metabolism. Thus, plasticity allows a species to develop short-term adaptations, in addition to longterm genetic adaptations that occur as a result of natural selection. However, any event that interferes with the correct communication between the environment and the fetus can lead to the appearance of a phenotype not adjusted to the ecological niche, increasing the risk of generating diseases in the long term.

Considering the aforementioned example, if the mother's poor nutrition does not reflect the reality of the environment, the establishment of a "saver" phenotype in the offspring in a nutrient-rich environment in postnatal life will lead to an increased risk of obesity and the multiple associated complications to this condition. ${ }^{12,21-23}$ Low birth weight (LBW), prematurity, restricted fetal growth and fetal macrosomia predisposes to a higher risk of developing NCDA. ${ }^{24,25}$ This explains how pre-gestational obesity and excessive weight gain during pregnancy are implicated in the transgenerational cycle of obesity. In summary, the quality of maternal nutrition, exposure to steroid hormones, stress or the presence of pathologies during pregnancy, such as gestational diabetes and pre-eclampsia, have long-term effects on metabolic, cardiovascular, reproductive and neurological function in postnatal life. ${ }^{17}$ Regarding kidney diseases, un unfavorable intrauterine environment could cause adaptations of the embryo/fetus resulting in compromised renal maturation. This sequence of events is called fetal and perinatal programming of kidney diseases in adults (Figure 1). ${ }^{26,27}$

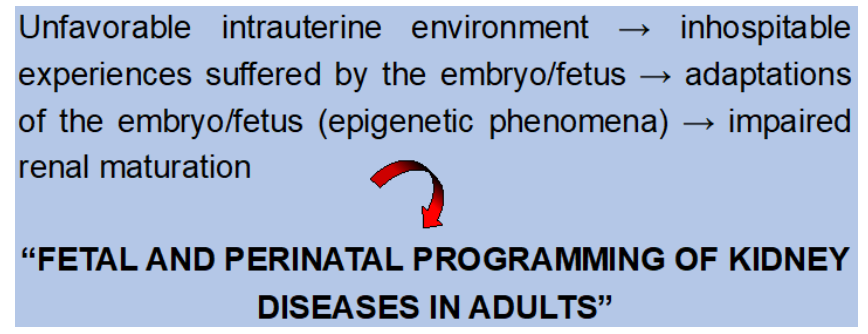

Figure I Sequence of events in embryo/fetus resulting in fetal and perinatal programming of kidney diseases in adults.

The main mechanisms of fetal and postnatal development of adult kidney diseases are: number of nephrons, size of the nephrons, integrity of the telomeres, and genetic and hormonal factors. During normal development, the size of the telomeres and their maintenance mechanisms allow for sufficient cell divisions to maintain the subsequent cell integrity of the postnatal organ system. In contrast, in babies with LBW, a postnatal "catch-up" period may be associated with telomere shortening, possibly requiring the recruitment and premature exhaustion of renal stem cells or progenitors. Consequently, the kidney's ability to do a cell turnover after an injury can be compromised and make these individuals more susceptible to damage. ${ }^{26,27}$ There is evidence to support the association between LBW and the increased prevalence of hypertension and CKD in adulthood. Several potential mechanisms for this association are proposed, especially the hypothesis of the low number of nephrons and molecular and cellular mechanisms. ${ }^{28}$ Newborns can be divided into preterm, full-term or post-term according to gestational age, and can be divided into appropriate for gestational age (AGA), small for gestational age (SGA) or large for age gestational age (LGA), according to birth weight. Both preterm infants and full-term newborns can be AIG and SGA. Animal and human studies have shown an association between a reduced number of nephrons and newborns PIG. ${ }^{29}$ Fetal growth restriction (FGR) due to protein restriction in the diet also resulted in reduced number of nephrons and CKD in rats. ${ }^{30}$

Full-term newborns usually have a complete number of nephrons. However, premature newborns may have a reduced number of nephrons due to FGR, impaired pregnancy, inadequate postnatal nutrition and treatment with medications, such as non-steroidal anti-inflammatory drugs after birth. ${ }^{31}$ A nephron deficit can lead to increased glomerular capillary pressure, hyperfiltration, compensatory glomerular and tubular hypertrophy. It begins a cycle of further loss of nephrons and consequent evolution to progressive loss of renal function. ${ }^{32,33}$ Epidemiological studies support the statement that LBW and prematurity are risk factors for kidney disease in adulthood and in both situations there is a reduced number of nephrons. ${ }^{31,34}$ Systematic review with more than two million babies with LBW concluded that these babies are at higher risk for developing chronic kidney disease (OR 1.73, CI 95\%-1.44 to 2.08) ${ }^{35}$ Case-control study with approximately 2,000 children with CKD identified several prenatal and maternal factors, such as LBW, maternal gestational diabetes and maternal obesity, increasing the risk of CKD. ${ }^{36}$ A study carried out through Renal Registry and the Medical Birth Registry of Norway between the years $1967-2004$ showed that among the 2,138,317 births in the period, 526 evolved with terminal CKD. BPN had a 
risk of $1.7(95 \%$ CI $1.4-2.2 ; \mathrm{p}=0.001)$ to progress to terminal $\mathrm{CKD}$ and PIG a risk of 1.5 (95\% CI 1.2-1.9; $\mathrm{p}=0.002) .{ }^{37}$ Yzydorczyk et $\mathrm{a}^{36}$ in 2017 showed that individuals born with FGR are at increased risk of endothelial dysfunction, arterial hypertension, atherosclerosis, coronary heart disease and CKD. ${ }^{38}$

\section{Prevention of kidney diseases in childhood}

Considering all the evidence, in April 2016 a Workshop was held with the aim of highlighting the association between fetal and child development and the increased risk of adult diseases, with a focus on arterial hypertension and CKD. The need for early actions to prevent CKD and other non-communicable diseases was highlighted, based on the assertion that an early understanding of the intrauterine determinants of renal mass development allows the opportunity for early interventions and effective prevention. ${ }^{39}$ Pediatricians have the real opportunity to effectively prevent kidney disease. They can identify patients at risk, patients already affected, and prevent disease progression, preventing persistent kidney damage. CKD prevention can be done in three stages:

Primary prevention: primary prevention aims to eliminate or reduce exposure to factors that cause kidney disease.

Secondary prevention: secondary prevention aims to prevent the reduction of the glomerular filtration rate, preventing progression to CKD.

Tertiary prevention: tertiary prevention aims to reduce or postpone CKD complications in long term. ${ }^{40,41}$

It is very important to emphasize that the best prevention would be the primary. In order to make effective prevention in childhood, it is necessary to know the epidemiology of CKD in this age group, to know how to assess the renal function of children and adolescents and to know how to identify the population at risk. Most of the existing epidemiological data on CKD in children and adolescents are concentrated mainly in information from tertiary centers. European pediatric nephrology societies have provided data on the early stages of CKD. ${ }^{2,46,47}$ Its incidence was 11 to 12 per million of the same age population (pmpi) for CKD stages 3 to 5 , and 8 pmpi for CKD stages 4 to 5 . The prevalence varied from 55 to 60 to 70 to 75 pmpi in Spain and Italy, depending on the clinical definition of CKD that was being used in each study. Another consistent finding was the predominance of males (male/female ratio 2.0 to 1.3 ), which reflects, in particular, the higher incidence of CAKUT in boys than in girls. ${ }^{5}$ Study conducted in Latin American countries (Argentina, Brazil, Chile, Colombia, Mexico, Uruguay and Venezuela) showed wide variation in incidence: from 2.8 to 15.8 new cases of pmpi. ${ }^{48}$ In Chile, a national survey estimated an incidence of 5.7 pmpi and a prevalence of 42.5 pmpi in children under 18 years of age. ${ }^{49}$

Considering the Middle East and Southeast Asia, an average incidence of 38 pmpi was found in a reference center in Kuwait. The prevalence increased from 188 in 1996 to 329 pmpi in 2003. ${ }^{50}$ In Jordan there was an incidence of 11 pmpi and a prevalence of 51 pmpi. $^{51}$ A study carried out at a single center in Africa showed an estimated incidence of 3 pmp in Nigeria. ${ }^{52}$ Peco-Antic et al ${ }^{52}$ in 2012, showed the results of the Serbian Pediatric Chronic Kidney Disease Registry (SPRECKID). The median annual incidence of CKD in stages 2 to 5 was 14.3 per million population of the same age group, while CKD in stages 2 to 4 or CKD 5 were 9.1 and 5.7 pmip, respectively. The median prevalence of CKD in stages 2 to 5 was 96.1 pmip, 52.8 pmip for CKD in stages 2 to 4 , and 62.2 pmip for CKD $5 .{ }^{4}$ Study conducted in Brazil with 1283 pediatric patients on chronic dialysis showed a prevalence of 20 cases per million population of the same age and an incidence of 6.6 cases per million population of the same age..$^{53}$

Renal function should not be assessed by blood values of creatinine and urea. Creatinine is a late marker of kidney function and has some limitations that should be considered. The best method is to assess glomerular filtration, which is defined as the clearance of a substance over a period of time. This substance must be freely filtered, not reabsorbed and not secreted by the renal tubules, it must not undergo renal metabolism, nor should it bind to proteins. The substances that best fulfill these prerequisites are inulin and cystatin C. Inulin is an exogenous substance and needs to be infused for 24 hours to calculate its clearance. Cystatin C is a low molecular weight protein, whose serum concentration correlates better with glomerular filtration, and pediatric reference values are 0.7 to $1.38 \mathrm{mg} / \mathrm{L}$. The formula for calculated creatinine clearance is:

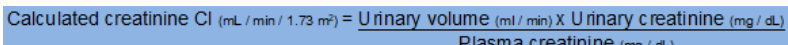

Plasma creatinine $\mathrm{mg} / \mathrm{dL}$

This calculation requires a 24-hour urine collection. The difficulty of this collection in children and the possibility of collection errors must be considered. Furthermore, it would not be possible to use it for children without urinary sphincter control. In 1976, Schwartz and collaborators developed a formula for estimating creatinine clearance that did not consider urinary creatinine, and therefore 24-hour urine collection is not necessary ${ }^{54}$ :

\section{Estimated creatinine $\mathrm{Cl}\left(\mathrm{mL} / \mathrm{min} / 1.73 \mathrm{~m}^{2}\right)=$ Height $(\mathrm{cm}) \times \mathrm{K}$ Plasma creatinine $(\mathrm{mg} / \mathrm{dL})$}

The constants $(\mathrm{K}=$ constant $)$ varied according to the age groups:

I. 0.31 (premature)

II. 0.33 (infant up to 12 months malnourished)

III. 0.45 (infants up to 12 months eutrophic)

IV. 0.55 (female adolescents)

V. 0.7 (male adolescents).

In 2009, Schwartz and collaborators reevaluated this formula and concluded that it could overestimate the renal function of children and it was decided that the value of constant $\mathrm{K}$ would be 0.413 for all age groups, starting at one year of age. ${ }^{55}$ The new formula is:

Estimated creatinine $\mathrm{Cl}_{\left(\mathrm{mL} / \mathrm{min} / 1.73 \mathrm{~m}^{2}\right)}=\frac{\text { Height }(\mathrm{cm}) \times 0.413}{\text { Plasma creatinine }(\mathrm{mg} / \mathrm{dL})}$

$\mathrm{K}=$ constant

0.31 (premature)

0.33 (infant up to 12 months malnourished)

0.45 (infants up to 12 months eutrophic)

In order to have good prevention in childhood, it is necessary to know how to identify the pediatric population at risk for CKD. Children and adolescents considered at risk and who should be screened are those with:

I. Family history of CKD or other genetic kidney disease

II. Family history of hypertension, diabetes and cardiovascular disease in parents, uncles and grandparents

III. Low birth weight and premature babies

IV. History of long hospital stay in the neonatal period

V. Renal dysplasia / hypoplasia

VI. Spinal cord tumors and traumas 


\section{Congenital malformations of the urinary tract}

VIII. Previous history of hemolytic-uremic syndrome

IX. Previous history of glomerulopathies

X. Overweight / obese children

XI. Bladder diseases (neurogenic, non-neurogenic bladder, lower urinary tract dysfunction).

\section{How to prevent CKD in childhood}

There are many preventive actions that can be developed before pregnancy, during the gestational period and from early childhood to adolescence to prevent the occurrence of kidney damage or to prevent the progression of the injury.

\section{Primary preventive strategies}

1. Control of possible future pregnancy:

Avoid using drugs (angiotensin converting enzyme (ACE) Inhibitors, angiotensin 11 receptor blockers, non-steroidal antiinflammatory drugs, illicit drugs)

I. Control of overweight/obesity and metabolic syndrome

II. Control of dyslipidemia

III. Pay attention to the future mother's nutrition

IV. Prevent disease (rubella, toxoplasmosis, cytomegalovirus, etc.)

V. Guide on the importance of genetic counseling

VI. Use folic acid.

To achieve these goals, obstetricians and gynecologists must be guided and involved in the "Prevention" objective. Studies have shown a correlation between the rate of hospitalizations of newborns and a higher pre-pregnancy maternal body mass index (BMI), especially when above 40. In the last decade, there has been an increase in BMI among pregnant women. In Canada, among 24,451 deliveries, 35\% of pregnant women had a BMI $>25$, with a correlation between maternal obesity and a higher BMI and arterial hypertension in childhood. The relative risk of developing CKD rises from 1.87 for BMI between 25 and $29.9 \mathrm{~kg} / \mathrm{m}^{2}$ to 7.07 for $\mathrm{BMI} \geq 40 \mathrm{~kg} / \mathrm{m}^{2} .{ }^{42}$

2. Control of the pregnant woman:

- Avoid using drugs (angiotensin converting enzyme (ACE) Inhibitors, angiotensin receptor blockers, non-steroidal antiinflammatory drugs, illicit drugs)

I. Control of overweight / obesity and metabolic syndrome

II. Control of dyslipidemia

III. Pay attention to the future mother's nutrition

IV. Prevent disease (rubella, toxoplasmosis, cytomegalovirus, etc.)

V. Prohibit the use of tobacco and alcohol

VI. Prevent prematurity, if possible

VII. Early detection of intrauterine growth restriction.

In the same way, to achieve these goals, obstetricians and gynecologists must be guided.

The use of teratogenic drugs such as alcohol, cocaine, alkylating agents, valproic acid and others can cause renal malformations.
Intrauterine exposure to medications can also result in kidney damage to the newborn. The use of aminoglycoside, corticoid and lactamine can result in reduction in the number of nephrons. In addition, aminoglycosides can trigger a defect in cell division; corticosteroids can favor the occurrence of arterial hypertension and albuminuria; and lactamines can favor tubular dilatation. Ceftriaxone can cause interstitial nephritis, angiotensin converting enzyme (ACE) Inhibitors and non-steroidal anti-inflammatory drugs can induce renal tubular dysgenesis, fetal anuria and even neonatal death. Prematurity and FGR with LBW can be consequences of gestational situations that could be avoidable such as: compromised nutritional status, use of drugs such as angiotensin converting enzyme (ACE) Inhibitors, use of tobacco, alcohol or drugs and maternal urinary tract infection. These children are born with a reduced number of nephrons since intrauterine nephrogenesis occurs up to 35 to 36 weeks, with $60 \%$ occurring in the third trimester. Postnatal nephrogenesis is not similar to prenatal, neither in quality nor in quantity. Add to this, the condition risk factors inherent to preterm infants, such as high propensity for acute kidney injury, use of medications with a higher risk of impaired renal function in the long term. ${ }^{13,43}$ Obesity in pregnancy exposes the mother and baby to the risks of pre-eclampsia, diabetes with teratogenic effect and renal dysplasia, prematurity, FGR, large birth weight (LGA) with increased risk of metabolic syndrome, congenital renal and neural tube abnormalities, in addition to requiring cesarean delivery with a higher risk of perinatal morbidity. The deficit of folic acid in pregnant women is the cause of defects in the neural tube with consequent myelomeningocele and neurogenic bladder. ${ }^{44}$ The diagnosis and treatment of infections during pregnancy are also important, as they are potentially teratogenic and can result in glomerulopathies (syphilis, toxoplasmosis, cytomegalovirus, HIV).

\section{Infant control:}

Avoid using drugs in the lactating mother (angiotensin converting enzyme (ACE) Inhibitors, angiotensin 11 receptor blockers, nonsteroidal anti-inflammatory drugs, illicit drugs, smoking and alcohol)

I. Stimulate breastfeeding

II. Take care of infant nutrition

III. Attention to secondhand smoke

IV. Watch out for postnatal catch up.

Again, to achieve these goals, pediatricians and parents / caregivers must be oriented and involved. Children who receive exclusive breastfeeding seem to have lower blood pressure levels in long-term follow-up. Saturated fats can raise cholesterol levels early in life, but liver regulation of lipoproteins produces a more favorable posterior profile. The consumption of artificial formulas has been associated with higher blood pressure levels, however, there is still no consensus on this topic. In preterm infants, a greater supply of proteins results in increase in the glomerular filtration rate (GFR) and renal mass. Here too, there is no consensus about the impact on future renal function or the occurrence of arterial hypertension, related to osmotic load and hyperfiltration. On the other hand, evidence demonstrates that very fast weight gain in the first months of life implies an increased risk of developing hypertension. However, nutritional restriction with reduced nephrons has a possible negative impact on renal development.

Prematurity, with glomerular and tubular immaturity, lower GFR and maximum urinary osmolarity can result in a greater possibility of acute kidney injury and nephrocalcinosis. There are reports of $27 \%$ to $64 \%$ of premature infants developing nephrocalcinosis due to 
iatrogenic hypercalciuria, prolonged parenteral nutrition, prolonged oxygen therapy, imbalance between promoters and crystallization inhibitors, administration of furosemide, dexamethasone and aminoglycosides. ${ }^{35-37,45}$

\section{Child and adolescent control:}

I. Prevent overweight / obesity and dyslipidemia

II. Promote food education

III. Encourage physical activity

IV. Encourage breastfeeding

V. Prohibit the use of tobacco and alcohol.

To achieve these goals, pediatricians, health professionals, parents / caregivers, schools, day care centers and the community must be involved and guided. The main approaches to the prevention of CKD in children and adolescents are the promotion of food education and the encouragement of physical activity. For healthy eating and physical activity to be effectively incorporated, awareness and involvement of pediatricians, other health professionals, parents/caregivers, schools, day care centers and the community are necessary. Humanity's eating habits have undergone considerable changes. It is necessary to keep in mind that the food standards are established in the first two years of life and it is during this period that the child's taste buds are formed. If the child receives adequate guidance during this period, the child will always have a good diet and will not develop overweight/obesity. The critical periods in childhood for the development of overweight/ obesity in adulthood are: the prenatal period, at age five, and adolescence. And several complications of overweight and obesity start in childhood, such as hypertension (which is higher in obese children), diabetes mellitus, urinary stones, dyslipidemia that favor atherosclerosis and cardiovascular events, and obesity in adulthood.

Regarding the presence of dyslipidemia, we must always assess the presence of secondary causes, presence of family disorders of lipoprotein metabolism, screen other family members, assess the family history of smoking. It is very important to advise parents about the risks of secondhand smoke. and after two years of age, foods rich in: saturated fats ( $<10 \%$ of daily calories), cholesterol ( $<300 \mathrm{mg}$ / day), trans fatty acids, and sugar consumption should be limited. ${ }^{56}$ Physical activity is another very important aspect and should be encouraged from an early age. The recommendations of the World Health Organization are: 60 minutes of moderate to vigorous activity per day for children and adolescents and according to age, participation in age-appropriate household activities (sweeping, making beds, storing toys, etc). The use of electronics devices (television, computers, games and cell phones) for a maximum of two hours a day, and family outings that include hiking, biking, swimming or other recreational activities. The family, the community, parents / caregivers, teachers, and doctors must be a positive role model for children and adolescents. In summary, the main agents for primary prevention are doctors and other health professionals, parents or caregivers, schools and day care centers, and the community. Doctors and other health professionals must be well prepared to guide families and children / adolescents, to monitor children / adolescents and must be an example, participating in educational activities. Parents and caregivers must have a healthy lifestyle:

I. To avoid soft drinks, industrialized juices, sweets, sausages, canned goods, salt;

II. Provide a diet rich in fruits, vegetables, milk and with a reduced content of saturated fats;
III. Ensure adequate intake of potassium with many fruits;

IV. To avoid quick and processed snacks;

V. Do regular physical exercises and be an example;

VI. To avoid second hand smoke;

VII. To read labels to check the content of the food.

Schools and day care centers should include curricular content on nutrition, notions of food hygiene, balance of food, and rational use of food resources in the training of their teachers.

\section{Secondary preventive strategies}

1. Postnatal preventive measures should include (pay attention to):

I. Low birth weight and extremely premature infants

II. Postnatal nutrition

III. Monitoring of albuminuria and blood pressure

IV. Appropriate and early approach to sepsis and the possibility of acute kidney injury

V. Early correction of metabolic disorders (polyuria, hyperkalaemia, bicarbonaturia, etc)

VI. Beware of clinical situations where there is a reduction in the number of nephrons (renal agenesis, vesicoureteral reflux grades IV and $\mathrm{V}$, obstruction of the ureteropelvic and ureterovesical junction)

VII. Attention to nephrotoxic drugs (angiotensin converting enzyme (ACE) Inhibitors, angiotensin 11 receptor blockers, non-steroidal anti-inflammatory drugs, antibiotics - aminoglycosides)

VIII. Be careful with the use of nephrotoxic contrasts

IX. Early correction of hypovolemia and shock with rapid replacement and volume maintenance

$\mathrm{X}$. Appropriate and early approach to urinary tract infection, especially in the first two years of life

XI. Appropriate and early approach to glomerulopathies (proteinuria, BP, dyslipidemia)

XII. Control of metabolic diseases (glycemic control, dyslipidemia, proteinuria, blood pressure)

XIII. Attention to rare diseases.

It is very important to avoid neonatal hypoxia, institute appropriate treatment of respiratory distress, maintain hemodynamic balance, avoid hypovolemia with an adequate supply of fluids and electrolytes, avoid the use of nephrotoxic drugs, and limit venous and arterial umbilical catheterizations that can cause thrombosis in vein or renal artery. These measures reduce the incidence of secondary arterial hypertension and acute kidney injury with its possible sequelae. ${ }^{57}$

The presence of urinary tract infection (UTI) should be considered as a sign of anatomical or functional abnormality of the urinary tract since uropathies are very common causes of CKD in children and adolescents. The recurrence of febrile UTI is related to the occurrence of secondary renal scarring. These scars can result in hypertension in $10 \%$ of the cases, proteinuria and progression to CKD. Thirty-eight to $50 \%$ of adults with renal scarring become hypertensive, with a risk of deterioration of renal function during pregnancy.$^{58}$ The development 
of adequate urinary and bowel habits reduces the occurrence of urinary tract disorders, as well as their early diagnosis and treatment are important to avoid high bladder pressures and recurrent UTI that can cause kidney damage. Currently, the symptoms of enuresis, urinary incontinence and urgency, urinary retention maneuvers, changes in urinary flow are signs of lower urinary tract dysfunction. The possibilities of pharmacological or physiotherapy treatment allow not only the improvement of symptoms, but also the prevention of secondary vesicoureteral reflux and reflux nephropathy. ${ }^{59}$

Children with congenital malformations, such as hypoplasia, dysplasia or renal agenesis, have reduced functional renal mass and it is necessary to protect the remaining nephrons. In some cases, the use of drugs as angiotensin converting enzyme (ACE) Inhibitors angiotensin 11 receptor blockers is indicated to prevent the progression of CKD. ${ }^{59}$

Some nephropathies, such as glomerulonephritis by immune deposits of IgA, can be detected at the beginning of school screening with the finding of proteinuria and/or hematuria. This screening is applied systematically in Japan, but the American Academy of Pediatrics does not recommend systematic performance, since the positive results that modify the therapeutic approach are low. For acute diffuse glomerulonephritis and hemolytic and uremic syndrome, periodic follow-up with occasional early intervention, use of drugs that slow progression and control of arterial hypertension is recommended. Monitoring and treatment of proteinuria, known as a risk factor for the progression of kidney disease, is essential. In this case the goal should be to keep proteinuria below $300 \mathrm{mg} / \mathrm{m}^{2} /$ day. ${ }^{59}$ If there is a family history of hereditary nephropathies (polycystic disease, nephronophtiasis, Alport's syndrome, family nephrotic syndrome, cystinosis) periodic follow up with possible renal protection measures and genetic counseling are mandatory.

Early diagnosis and timely treatment of tubulopathies, especially distal tubular acidosis and Bartter's syndrome, can prevent progression to nephrocalcinosis. The diagnosis should be suspected in the presence of growth retardation, rickets, changes in the electrolyte and basic acid balance, arterial hypertension and urolithiasis. ${ }^{59}$ Urolithiasis causes obstruction, favors urinary infections due to urinary stasis and may be accompanied by nephrocalcinosis. It is important to eliminate the calculus with appropriate techniques and make an anatomical and metabolic studies. Some of these diseases have a genetic basis and specific treatment. ${ }^{60}$ The neurogenic bladder is a special situation almost always secondary to neural tube defects and it is essential to perform an early anatomical and urodynamic study to detect high pressure bladders related to the greater occurrence of renal damage and CKD. Pharmacotherapy and early intermittent catheterization may be indicated. In a study of 312 patients with myelomeningocele, $23 \%$ had renal scars with a positive correlation with febrile UTI, vesicoureteral reflux and detrusor hyperactivity with dyssynergy. ${ }^{61}$ Lower urinary tract disorders cause recurrent infection, vesicoureteral reflux in about $30 \%$, are frequent in childhood and appear at 7 years of age in 5 to $10 \%$ of cases. The most severe cases of functional obstruction of the lower urinary tract can lead to CKD. Treatment is long with anticholinergics, pelvic floor biofeedback and neuromodulation..$^{59}$

High blood pressure is a major cause of progressive kidney damage. It can be suspected early in school screening or at the pediatrician's office, and can be confirmed through ambulatory blood pressure monitoring (ABPM), which has good reproducibility in the pediatric range. Although the most frequent cause in pediatric patients is renal, the prevalence of obesity-related primary arterial hypertension, metabolic syndrome and family history have increased significantly in this age group..$^{59,62}$ The use of renoprotective drugs allows to control hypertension, reduce eventual proteinuria and improve kidney survival. These drugs have vasodilatory action on arterioles, reduce glomerular pressure and hyperfiltration, have antiproteinuric effect, antiproliferative and antifibrotic actions, and reduce angiotensin II. ${ }^{59}$ The early diagnosis of uncommon hereditary diseases and rare diseases with the potential to develop CKD (cystinosis, Fabry's disease, atypical hemolytic uremic syndrome, etc.) is very important considering that therapeutic intervention can delay or prevent progression to CKD. ${ }^{59}$ Future perspectives in the field of molecular biology will allow the determination of genetic markers for many diseases, enabling early diagnosis and treatment.

\section{Tertiary preventive strategies}

For tertiary preventive measures, the most important will be cited and will be the subject of another article:

I. Blood pressure control

II. Proteinuria control

III. Dyslipidemia control

IV. Diet control (protein and phosphorus)

V. Anemia control

\section{Vitamin D normalization}

VII. Bone mineral disease control

VIII. Metabolic acidosis control.

\section{Conclusion}

A large number of clinical and pathological conditions can cause kidney damage in children and adolescents. Early recognition and the establishment of preventive measures can reduce morbidity, mortality and the economic burden due to CKD. Care must always be taken to avoid the onset and progression of CKD in childhood. Primary education and prevention campaigns to improve cardiovascular and kidney health have been developed in adults, however, it is necessary to remember that most risk factors in adults can start in childhood such as obesity, high blood pressure, dyslipidemia, diabetes, atherosclerosis, chronic pyelonephritis or obstructive uropathies.Finally, it is very important to highlight that prevention actions must be developed from childhood: "The prevention of kidney disease starts before pregnancy, during pregnancy and in childhood! We doctors, parents, caregivers, schools and the community are responsible!”.

\section{Acknowledgments}

Authors thank their patients.

\section{Declaration of conflicts of interest}

Author declare that there is no conflict of interest.

\section{Indication of authors' contribution}

Rejane de Paula Bernardes, Nilzete Liberato Bresolin and Maria Goretti Moreira Guimarães Penido were responsible for the research idea data acquisition, supervision and text writing. 


\section{References}

1. Warady BA, Chadha V. Chronic kidney disease in children: The global perspective. Pediatr Nephrol. 2007;22:1999-2009.

2. Ardissino G, Dacco V, Testa S, et al. Epidemiology of chronic renal failure in children: data from the ItalKid project. Pediatrics. 2003;111:e382-e387.

3. Collaborative Studies NAPRTCS, 2014 Annual Transplant Report. 2014. p.102.

4. Peco-Antic' A, Bogdanovic' R, Paripovic' D, et al. Epidemiology of chronic kidney disease in children in Serbia. Nephrol Dial Transplant. 2012;27:1978-1984.

5. Harambat J, van Stralen KJ, Kim JJ, et al. Epidemiology of chronic kidney disease in children. Pediatr Nephrol. 2012;27:363-373.

6. Greenbaum LA, Warady BA, Furth SL. Current Advances in Chronic Kidney Disease in Children: Growth, Cardiovascular, and Neurocognitive Risk Factors. Semin Nephrol. 2009;29:425-434.

7. Rees L. Long-term outcome after renal transplantation in childhood. Pediatr Nephrol. 2009;24:475-484.

8. Shroff R, Rees L, Trompeter R, et al. Long-term outcome of chronic dialysis in children. Pediatr Nephrol. 2006;21:257-264.

9. Levey AS, Schoolwerth AC, Burrows NR, et al. Comprehensive public health strategies for preventing the development, progression, and Complications of CKD: report of an expert panel convened by the Centers for Disease Control and Prevention. Am J Kidney Dis. 2009;53:522-535.

10. Levey AS, Andreoli SP, DuBose T, et al. Chronic kidney disease: Common, harmful, and treatable - World Kidney Day 2007. Am J Kidney Dis. 2007;49:175-179.

11. Nüsken E, Dötsch J, Weber LT, et al. Developmental Programming of Renal Function and Re-Programming Approaches. Front Pediat. 2018;6:36.

12. Terstappen F, Titia Lely A. Long-term renal disease after prematurity or fetal growth restriction: who is at risk? Nephrol Dial Transplant. 2020;35:1087-1090.

13. Filler G, Rayar MS, da Silva O, et al. Should prevention of chronic kidney disease start before pregnancy? Int Urol Nephrol. 2008;40:483488.

14. Barker DJP. The fetal and infant origins of adult disease. The womb may be more important than the home. BMJ. 1990;301:1111.

15. Bateson P, Barker D, Clutton-Brock T, et al. Developmental plasticity and human health. Nature. 2004;430:419-421.

16. Fowden AL, Giussani DA, Forhead AJ. Intrauterine programming of physiological systems: causes and consequences. Physiology (Bethesda). 2006;21:29-37.

17. Casanello P, Krauseb BJ, Castro-Rodrigueza JA, et al. Programación fetal de enfermedades crónicas: conceptos actuales y epigenética. Rev Chil Pediatr. 2015;86:135-137.

18. Hsu C, Tain Y. Early-Life Programming and Reprogramming of Adult Kidney Disease and Hypertension: The Interplay between Maternal Nutrition and Oxidative Stress. Int J Mol Sci. 2020;20:3572.

19. Maliqueo M, Echiburú B. Programación Fetal de las Enfermedades Metabólicas. Rev Farmacol Chile. 2014;7:33-46.

20. Casanello P, Schneider D, Herrera EA, et al. Endothelial heterogeneity in the umbilico-placental unit: DNA methylation as an innuendo of epigenetic diversity. Front Pharmacol. 2014;5:49.

21. Jansson T, Powell TL. Role of the placenta in fetal programming: Underlying mechanisms and potential interventional approaches. Clin
Sci. 2007;113:1-13.

22. Boersma GJ, Bale TL, Casanello P, et al. Long-term impact of early life events on physiology and behaviour. J Neuroendocrinol. 2014;26:587602 .

23. McMillen IC, MacLaughlin SM, Muhlhausler BS, et al. Developmental origins of adult health and disease: The role of periconceptional and fetal nutrition. Basic Clin Pharmacol Toxicol. 2008;102:82-89.

24. Kramer MS. The epidemiology of adverse pregnancy outcomes: An overview. J Nutr. 2003;133:1592S-1596S.

25. King JC. Maternal obesity, metabolism, and pregnancy outcomes. Annu Rev Nutr. 2006;26:271-291.

26. Hershkovitz D, Burbea Z, Skorecki K, et al. Fetal Programming of Adult Kidney Disease: Cellular and Molecular Mechanisms. Clin J Am Soc Nephrol. 2007;2:334-342.

27. The Low Birth Weight and Nephron Number Working Group. The Impact of Kidney Development on the Life Course: A Consensus Document for Action. Nephron Clin Pract. 2017;136(1): 3-49.

28. Zandi-Nejad K, Luyckx VA, Brenner BM. Adult hypertension and kidney disease: The role of fetal programming. Hypertension. 2006;47:502-508.

29. Brenner BM, Chertow GM. Congenital oligonephropathy: An inborn cause of adult hypertension and progressive renal injury? Curr Opin Nephrol Hypertens. 1993;2:691-695.

30. Woods LL, Weeks DA, Rasch R. Programming of adult blood pressure by maternal protein restriction: Role of nephrogenesis. Kidney Int. 2004;65:1339-1348.

31. Luyckx VA, Brenner BM. Birth weight, malnutrition and kidneyassociated outcomes - A global concern. Nat Rev Nephrol. 2015;11:135149

32. Bertram JF, Douglas-Denton RN, DioufB, et al. Human nephron number: Implications for health and disease. Pediatr Nephrol. 2011;26:15291533.

33. Brenner BM, Garcia DL, Anderson S. Glomeruli and blood pressure. Less of one, more the other? Am J Hypertens. 1988;1:335-347.

34. Luyckx VA, Bertram JF, Brenner BM et al. Effect of fetal and child health on kidney development and long-term risk of hypertension and kidney disease. Lancet. 2013;382:273-283.

35. White SL, Perkovic V, Cass A, et al. Is Low Birth Weight an Antecedent of CKD in Later Life? A Systematic Review of Observational Studies. Am J Kidney Dis. 2009;54(2):248-261.

36. Hsu CW, Yamamoto KT, Henry RK et al. Prenatal risk factors for childhood CKD. J Am Soc Nephrol. 2014;25:2105-2111.

37. Vikse BE, Irgens LM, Leivestad T, et al. Low birth weight increases risk for end-stage renal disease. J Am Soc Nephrol. 2008;19:151-157.

38. Yzydorczyk C, Armengaud JB, Peyter AC, et al. Endothelial dysfunction in individuals born after fetal growth restriction: cardiovascular and renal consequences and preventive approaches. J Dev Orig Health Dis. 2017;8:448-464.

39. The Low Birth Weight and Nephron Number Working Group. The Impact of Kidney Development on the Life Course: A Consensus Document for Action. Nephron. 2017;136:3-49.

40. Pecoraro C. Prevention of Chronic kidney disease (CKD) in children. Italian J Pediatrics. 2015;41:A56.

41. Hardy ST, Zeng D, Kshirsagar AV, et al. Primary Prevention of Chronic Kidney Disease through Population-Based Strategies for Blood Pressure Control: The Aric Study. J Clin Hypertens (Greenwich). 2018;20(6):1018-1026. 
42. Caggiani M, Halty M. Conceptos de nefroprevención. Arch Pediatr Urug. 2009;80:216-219.

43. Wani M, Kalra V, Agarwal SK. Low birth weight and its implication in renal disease. J Assoc Physicians India. 2004;52:649-652.

44. Mezzomo CL, Garcias GL, Sclowitz ML, et al. Prevention of neural tube defects: prevalence of folic acid supplementation during pregnancy and associated factors in Pelotas, Rio Grande do Sul States, Brazil. Cad Saude Publica. 2007;23:2716-2726.

45. Bacchetta J, Cochat P. Le rein des anciens prematurés est-il menacé? What about the long-term renal outcome of premature babies? Arch Pediatr. 2008;15:1212-1222.

46. Mong Hiep TT, Ismaili K, Collart F, et al. Clinical characteristics and outcomes of children with stage 3-5 chronic kidney disease. Pediatr Nephrol. 2010;25:935-940.

47. Bek K, Akman S, Bilge I, et al. Chronic kidney disease in children in Turkey. Pediatr Nephrol. 2009;24:797-806.

48. Orta-Sibu N, Exeni RA, G-arcia C. Latin America. In: Avner ED, et al., editors. Pediatric Nephrology. Springer-Verlag, Heidelberg, 2009, p. 1969-1974.

49. Lagomarsimo E, Valenzuela A, Cavagnaro F, et al. Chronic renal failure in pediatrics 1996. Chilean Survey. Pediatr Nephrol. 1999;13:288-291.

50. Al-Eisa A, Naseef M, Al-Hamad N, et al. Chronic renal failure in Kuwaiti children: an eight-year experience. Pediatr Nephrol. 2005;20:17811785 .

51. Hamed RM. The spectrum of chronic renal failure among Jordanian children. J Nephrol. 2002;15:130-135.

52. Anochie I, Eke F. Chronic renal failure in children: a report from Port Harcourt, Nigeria (1985-2000). Pediatr Nephrol. 2003;18:692-695.

53. Konstantyner T, Sesso R, de Camargo MF, et al. Pediatric Chronic Dialysis in Brazil: Epidemiology and Regional Inequalities. PLoS One.
2015; 10: e0135649.

54. Schwartz GJ, Haycock GB, Edelmann CM Jr, et al. A simple estimate of glomerular filtration rate in children derived from body length and plasma creatinine. Pediatrics. 1976;58(2):259-263.

55. Schwartz GJ, Muñoz A, Schneider MF, et al. New Equations to Estimate GFR in Children with CKD. J Am Soc Nephrol. 2009;20(3):629-637.

56. Expert Panel on Integrated Guidelines for Cardiovascular Health and Risk Reduction in Children and Adolescents, National Heart, Lung, and Blood Institute. Expert panel on integrated guidelines for cardiovascular health and risk reduction in children and adolescents: summary report. Pediatrics. 2011;128 (Suppl 5):S213.

57. Bresolin N, Silva C, Halllal A, et al. Prognosis for children with acute kidney injury in the intensive care unit. Pediatr Nephrol. 2009;24:537544.

58. Vachvanichsanong P. Urinary Tract Infection one lingering effect of childhood kidney diseases. J Nephrol. 2007;20:21-28.

59. Vijayakumar M, Nammalwar BR, Prahlad N. Prevention of chronic kidney disease in children. Indian J Nephrol. 2007;17:47-52.

60. Penido MGMG, Tavares MS. Pediatric primary urolithiasis: Symptoms, medical management and prevention strategies. World J Nephrol. $2015 ; 4: 444-454$.

61. Ozel Z, Dokumcu C, Akyildiz A, et al. Factors affecting renal scar development in children with spina bifida. Ulman Urol Int. 2007;79:13313.

62. Salvadori M, Sontrop JM, Garg AX, el al. Elevated blood pressure in relation to overweight and obesity among children in rural Canadian community. Pediatrics. 2008;122:821-827. 